\title{
Association between APOE genotype with body composition and cardiovascular disease risk markers is modulated By BMI in healthy adults: findings from the BODYCON study
}

\author{
E. Ozen ${ }^{1}$, R. Mihaylova ${ }^{1}$, N.J. Lord ${ }^{1}$, J.A. Lovegrove ${ }^{1}$ and K.G. Jackson ${ }^{1}$ \\ ${ }^{1}$ Hugh Sinclair Unit of Human Nutrition, Department of Food and Nutritional Sciences and Institute for \\ Cardiovascular and Metabolic Research and Institute for Food, Nutrition and Health, University of Reading, \\ Reading, $U K$
}

The relationship between APOLIPOPROTEIN ( $A P O) E$ genotype and cardiovascular disease (CVD) risk is extensively studied due to its effect on the plasma lipid profile ${ }^{(1)}$. However, studies investigating the associations between $A P O E$ genotype with CVD risk markers have generated inconsistent results, with a small number of human studies suggesting that BMI might play an important role in this relationship ${ }^{(2,3)}$.Therefore, we assessed the association between $A P O E$ genotype with body composition and CVD risk markers, with further examination of the role of BMI on this association.

BODYCON (impact of physiological and lifestyle factors on body composition) was a cross-sectional observational study in which 360 healthy men and women aged $18-70$ y with a BMI of $18.5-39.9 \mathrm{~kg} / \mathrm{m}^{2}$ underwent a measure of body composition by dual energy x-ray absorptiometry, assessment of physical activity level using a tri-axial accelerometer and habitual dietary intake using a 4-day weighed food diary. Circulating lipid CVD risk markers were measured in a fasting blood sample and participants were genotyped retrospectively for $A P O E$ (rs429358 and rs7412). A general linear model was used to determine the impact of genotype on body composition measures and CVD risk markers, and interaction between $A P O E$ and BMI on these outcome measures.

In the study cohort, $\mathrm{n}=46$ participants were $A P O E 2 / E 3, \mathrm{n}=228$ the wild type $A P O E 3 / E 3$ group and $\mathrm{n}=81 E 4$ carriers $(A P O E 3 /$ $E 4$ and $A P O E 4 / E 4)$. The $A P O E 2 / E 3$ group had on average $9 \%-18 \%$ lower fasting total, low-density lipoprotein and non-high density lipoprotein cholesterol concentrations compared to the $A P O E 4$ carrier and $A P O E 3 / E 3$ groups (p $\leq 0.01)$. Significant $A P O E$ x BMI interactions were observed for body weight and android fat mass $(\mathrm{p} \leq 0.01)$. When the group were stratified into normal-weight and overweight/obese BMI groups, lean body mass was $6.4 \%$ lower in the $A P O E 3 / E 3$ group (mean $\pm \mathrm{SE}, 45.2 \pm 0.5 \mathrm{~kg}$ ) compared to the APOE4 carriers $(48.1 \pm 0.9 \mathrm{~kg})$ in the normal BMI group $(\mathrm{p} \leq 0.02)$, while in the overweight/obese BMI group, the android:gynoid fat ratio was $7.6 \%$ lower in the $A P O E 4$ carriers $(1.10 \pm 0.03)$ compared to the $A P O E 3 / E 3$ group $(1.19 \pm 0.02)(\mathrm{p}=0.04)$.Differences in fasting lipid concentrations between the $A P O E 2 / E 3$ and other genotype groups was only found within the normal weight (p $\leq$ 0.04 ) but not overweight/obese BMI subgroup. Moreover, the $A P O E 2 / E 3$ participants within the normal-weight BMI group had a lower dietary fibre and trans-fat intake compared to the APOE4 carriers and lower carbohydrate intake compared to the $A P O E 3 /$ $E 3$ group while there were no differences between genotypes in the overweight/obese BMI group. Physical activity levels were similar between genotype groups within each BMI group.

Our findings confirm previous studies suggesting that the impact of $A P O E$ genotype on CVD risk markers is modulated by BMI but indicate that diet may also play a role in this relationship. Further research is needed to draw a firm conclusion on the underlying mechanisms.

\section{References}

1. Bennet AM, Di Angelantonio E, Ye Z et al. (2007) Jama 298, 1300-1311.

2. Kofler BM, Miles EA, Curtis P et al. (2012) Atherosclerosis 221, 467-470.

3. Minihane AM, Khan S, Leigh-Firbank EC et al. (2000) Arterioscler Thromb Vasc Biol 20, 1990-1997. 